\title{
Factors Associated with Providers' Work Engagement and Burnout in Homeless Services: A Cross-national Study
}

\author{
Michela Lenzi, ${ }^{1}$ Massimo Santinello, ${ }^{1}$ Marta Gaboardi, ${ }^{1}$ Francesca Disperati, ${ }^{1}$ Alessio Vieno, ${ }^{1}$ Antonio Calcagnì, \\ Ronni Michelle Greenwood, ${ }^{2}$ Aleksandra M. Rogowska, ${ }^{3}$ Judith R. Wolf, ${ }^{4,5}$ Sandrine Loubière, ${ }^{6,7}$ Ulla Beijer, ${ }^{8}$ \\ Roberto Bernad, ${ }^{9}$ Maria J. Vargas-Moniz, ${ }^{10}$ José Ornelas, ${ }^{10}$ Freek Spinnewijn, ${ }^{11}$ Marybeth Shinn, ${ }^{12}$ and \\ HOME_EU Consortium Study Group
}

\section{Highlights}

- The complexity of users' characteristics can make working with homeless people very stressful.

- Some features of homeless services are likely to be associated with providers' well-being.

- Useful training was associated with higher levels of work engagement and lower levels of burnout.

- Non useful supervision was positively associated with providers' burnout.

- Capability-fostering approach was positively associated with providers' well-being.

${ }^{\dagger}$ The members of HOME-EU Consortium Study Group are listed in Appendix 1.

Michela Lenzi

michela.lenzi@unipd.it

1 Department of Developmental and Social Psychology, University of Padova, Padua, Italy

2 Department of Psychology, University of Limerick, Limerick, Ireland

3 Institute of Psychology, Opole University, Opole, Poland

4 Impuls-Netherlands Center for Social Care Research, Radboud Institute for Health Sciences, Radboud, The Netherlands

5 University Medical Center, Nijmegen, The Netherlands

6 School of medicine - La Timone Medical Campus, EA 3279: CEReSS - Health Service Research and Quality of life Center, Aix-Marseille University, Marseille, France

7 Department of Research and Innovation, Support Unit for Clinical Research and Economic Evaluation, Assistance Publique Hôpitaux de Marseille, Marseille, France

8 STAD, Centre for Psychiatry Research, Department of Clinical Neuroscience, Karolinska Institutet, Stockholm, Sweden

9 Rais Fundación, Madrid, Spain

10 APPsyCI-Applied Psychology Research Center Capabilities and Inclusion, ISPA-Instituto Universitário, Lisboa, Portugal

11 FEANTSA, European Federation of National Organisations Working with the Homeless, Bruxelles, Belgique

12 Department of Human and Organizational Development, Peabody College, Vanderbilt University, Nashville, TN, USA
Abstract The complexity of homeless service users' characteristics and the contextual challenges faced by services can make the experience of working with people in homelessness stressful and can put providers' wellbeing at risk. In the current study, we investigated the association between service characteristics (i.e., the availability of training and supervision and the capabilityfostering approach) and social service providers' work engagement and burnout. The study involved 497 social service providers working in homeless services in eight different European countries $(62 \%$ women; mean age $=40.73, S D=10.45$ ) and was part of the Horizon 2020 European study "Homelessness as Unfairness (HOME_EU)." Using hierarchical linear modeling (HLM), findings showed that the availability of training and supervision were positively associated with providers' work engagement and negatively associated with burnout. However, results varied based on the perceived usefulness of the training and supervision provided within the service and the specific outcome considered. The most consistent finding was the association between the degree to which a service promotes users' capabilities and all the aspects of providers' well-being analyzed. Results are discussed in relation to their implications for how configuration of homeless services can promote social service providers' well-being and high-quality care.

Keywords Homelessness - Service - Training - Supervision . Capabilities · Burnout 


\section{Introduction}

Working in homeless services can be challenging for social service providers. People experiencing homelessness face huge health inequalities (Aldridge et al., 2018), such as, being disproportionately beset by physical and mental problems, substance abuse, and chronic diseases as compared to the general population (Beijer, Bruce, \& Burström, 2016; Lewer et al., 2019). In addition, people experiencing homelessness often report multiple health problems that are not addressed effectively by health services and have low levels of social support (van Dongen et al., 2019). Many of these health problems stem from traumatic experiences such as adverse childhood events (McDonagh, 2011), which contribute further to social exclusion and long-term homelessness (Deck \& Platt, 2015). Considering the complexity of their tasks, it is fundamental to identify the factors that protect social service providers working in homeless services from developing burnout symptoms and factors that promote a positive work experience. However, there are few studies that investigate the factors associated with providers' well-being in the field of homelessness, and the small amount of evidence in this area shows inconsistent associations between practitioner and organizational variables and providers' well-being (Lemieux-Cumberlege \& Taylor, 2019). Moreover, to our knowledge, no studies have adopted a cross-national approach in analyzing social service providers' work experience.

For these reasons, the current work aims to expand the existing literature by evaluating whether training, supervision, and a capability-fostering approach are associated with higher levels of work engagement and lower levels of burnout in a cross-national sample of providers working in homeless services.

In order to effectively promote clients' recovery, providers working in homeless services need a wide set of skills in several domains to deal with the multiple problems that people in homeless situations are facing and also to handle clients' complex relationship with care. Indeed, marginalized people often approach the relationship with providers with suspicion and mistrust (Conrad \& KellarGuenther, 2006; Knight, 2013), making the work of the staff even more challenging and potentially stressful (Knight, 2013). This is sometimes due to negative and stigmatizing experiences that service users may have had with providers (Martins, 2008), which contribute to the creation of an ambivalent relationship that needs to be repaired by providers working with an empowering approach.

Service users' clinical picture and their difficult relationship with the system of care, however, are not the only challenges of work in homeless services, which is also constrained by organizational, environmental, and political pressures. Providers working with people in extreme marginalization often face financial strain, unmanageable caseloads, high turnover, and a lack of clarity in the definition of roles and competencies (Kulkarni, Bell, Hartman, \& Herman-Smith, 2013; Osofsky, Putnam, \& Lederman, 2008). Financial crises, anti-begging laws, and the resulting negative public perception of marginalized people also politicize the role of providers working in homeless services. This role often requires collaboration with the local or national government administration, for example, involvement in advocacy activities, and additional demands on professional competencies and knowledge (Lemieux-Cumberlege \& Taylor, 2019).

The Experience of Working in Homeless Services: Providers' Work Engagement and Burnout

The complexity of service users' characteristics and contextual pressures can make the experience of working with people experiencing homelessness very stressful and lead providers to experience reduced work engagement (Berzoff \& Kita, 2010; Geoffrion, Morselli, \& Guay, 2016) and to develop stress and burnout symptoms (LemieuxCumberlege \& Taylor, 2019). Service providers' experience of work-related stress and low engagement with the role might in turn have detrimental consequences on the quality of care provided to service users (Figley, 2002; Henwood, Shinn, Tsemberis, \& Padgett, 2013; Manning \& Greenwood, 2018).

Work engagement can be defined as a positive feeling of involvement in work-related activities and goals (Schaufeli \& Bakker, 2003). Engaged workers report a sense of vigor, dedication, and absorption as part of their work experience. This fulfilling, work-related state of involvement of workers (Bakker, Albrecht, \& Leiter, 2011) was found to be associated with a number of positive work-related outcomes, such as motivation to reach the organization's goals and face the challenges associated with those goals, organizational commitment (Kanste, 2011), low turnover, and job satisfaction (Guglielmi et al., 2016). High levels of engagement have been also associated with workers' creativity and productivity, as well as physical and psychological health, which in turn are fundamental for the delivery of high-quality services (Figley, 2002; Schaufeli \& Bakker, 2004).

On the other hand, there is some evidence that the complexity of the role played by social service providers within homeless services might lead to the development of burnout (Bell, Kulkarni, \& Dalton, 2003; Kulkarni et al., 2013; Osofsky et al., 2008). Sometimes defined as the antithesis of engagement, burnout has been conceptualized as a syndrome characterized by exhaustion, 
relational deterioration, and a diminished sense of accomplishment resulting from a prolonged exposure to job stressors (Maslach, Schaufeli, \& Leiter, 2001). Emotional exhaustion is characterized by the feeling of being drained of energy and stressed out and represents the dimension of burnout most strongly associated with workers' wellbeing (Maslach \& Leiter, 2010); relational deterioration refers to a psychological withdrawal from work and clients, usually resulting from a dysfunctional attempt to deal with emotional exhaustion (Schaufeli \& Taris, 2005); diminished personal accomplishment indicates a negative evaluation of one's own job performance and its effectiveness (Maslach et al., 2001).

Over the years, the definition of burnout has been expanded in order to better understand the experience of health and care practitioners, who often choose the job based on a strong motivation to help others in need, and are sustained by "compassion satisfaction," that is, the psychological fulfillment deriving from giving support to people who are suffering (Wagaman, Geiger, Shockley, \& Segal, 2015). Considering the high expectations and the tendency to idealize the professional role, some authors proposed an additional dimension as part of the burnout syndrome: disillusionment (Santinello, Verzeletti, \& Altoè, 2006). This component refers to the feeling of disappointment when realizing the discrepancy between one's expectations about the job and the reality of work, in particular in relation to the goals achieved, the possibility of translating idealistic principles into practice, and the prestige associated with the professional role (Santinello et al., 2006).

In the field of homeless services, work-related stressors and the continuous exposure to trauma and suffering can reduce practitioners' ability to empathize with service users and their satisfaction with the professional role, while increasing a feeling of emotional exhaustion and a sense of disillusionment. Although a few studies on homeless service providers focused specifically on investigating burnout (e.g., Kulkarni et al., 2013; Osofsky et al., 2008; Young, 2007), there is evidence that care workers report higher levels of stress and depression symptoms compared to the general population (Kim, Ji, \& Kao, 2011; Lemieux-Cumberlege \& Taylor, 2019; Stanley, Manthorpe, \& White, 2007). Moreover, in services where users have very complicated histories and needs, like frontline homeless services, providers have been found to experience secondary traumatic stress (STS), the symptoms of which are very similar to post-traumatic stress disorder, including hypervigilance and avoidant coping strategies (Hensel, Ruiz, Finney, \& Dewa, 2015).

Considering the detrimental consequences that low levels of work engagement and high levels of burnout can have on the quality of the services delivered, and on other aspects of providers' well-being and work experience, it is critical to identify modifiable factors in homeless services protecting professionals from a negative work experience.

Factors Associated with Providers' Work Engagement and Burnout in Homeless Services

Existing literature has mixed findings in relation to individual and organizational factors that influence social service providers' work experience (see Bride, 2004, for a review). Regarding practitioners' characteristics, for example, age and work experience have been inconsistently associated with psychological distress; some studies support that being young and less experienced increases the likelihood of developing stress symptoms at work (Adams, Boscarino, \& Figley, 2006; Bride, 2004; Kulkarni et al., 2013) with professional experience being associated with higher levels of satisfaction (Craig \& Sprang, 2010); in other studies, older providers (Baird \& Kracen, 2006; Salloum, Kondrat, Johnco, \& Olson, 2015) and practitioners who have worked with psychological trauma for a long time (VanDeusen \& Way, 2006) experience higher levels of distress. Still other studies report that the time spent working in highly demanding services (e.g., services dealing with users' psychological traumas) has a greater impact on providers' work experience and well-being as compared to the time spent in care services in general (VanDeusen \& Way, 2006).

Besides individual characteristics, some service features have been associated with providers' work experience and well-being in contexts where they are exposed to users' complex needs and environmental stressors (e.g., homeless services). Staff training and supervision is one key strategy to support providers' work (Keats, Maguire, Johnson, \& Cockersell, 2012). Indeed, considering the wide array of competencies required by the professional role, it is plausible that training aimed at developing those skills could protect social service providers from reduced engagement with their work, and from burnout symptoms. In addition, having the chance to reflect on particularly complex cases with supervisors and colleagues might help homeless service providers in identifying the best strategies to promote clients' recovery and overcome organizational and environmental stressors.

The importance of training and supervision is emphasized in psychologically informed environments (PIE; Keats et al., 2012), which recognize how users' psychological needs and the complexity of the job can affect homeless service providers, and promotes a supportive work environment. Services that can be characterized as psychologically informed use a wide range of strategies aimed at increasing service providers' confidence in responding to users' challenging health and housing situations (Archard \& Murphy, 2015), and their ability to 
recognize early signs of reduced engagement and burnout. Along with formal trainings and supervision, reflective practice group (RPG), case review groups (CRG), and community of practice (COP) have been implemented in order to increase the opportunities to reflect on one's own work experience with colleagues and exchange knowledge, competencies, and good practices among colleagues. Although the literature evaluating the potential benefits of PIE is still scant (Lemieux-Cumberlege \& Taylor, 2019), there is some evidence showing that in homeless services, COP (i.e., groups composed of multi-disciplinary practitioners collaborating on case reviews) may have a protective role against the development of burnout and stress symptoms in social service providers (Cornes, Manthorpe, Hennessy, \& Anderson, 2013; Scanlon \& Adlam, 2012).

In addition to service features such as the availability of training and supervision for the staff, the general mission and the system of values adopted within the organization might have a crucial role in shaping providers' well-being. A number of studies showed that well-defined goals and principles, and the corresponding clear guidelines for coordinating the work of the staff in reaching those goals, are associated with a higher performance (Olivet, McGraw, Grandin, \& Bassuk, 2010; Stetler, Ritchie, Rycroft-Malone, Schultz, \& Charns, 2007). This is in line with Maton's model of empowering community settings (Maton, 2008), which states that empowering services are characterized by a clear mission and well-defined goals based on a strength-based approach (Gaboardi et al., 2019; Maton, 2008). According to this model, working in a service where the users are considered as resources with capabilities can promote higher levels of motivation among the staff. Having clear, strength-based goals might also facilitate the work of social service providers by guiding specific activities aligned with these goals, thus increasing the likelihood of reaching desired outcomes. Consistently, in a cross-national study, when asked about organizational characteristics supporting their work, providers working in homeless services mentioned a strength-based approach focusing on the development of clients' capabilities as one of the most relevant features (Gaboardi et al., 2019).

The emphasis on quality of life as an indicator of equality makes the capabilities approach particularly useful for evaluating the efficacy of homeless services (Sacchetto, Ornelas, Calheiros, \& Shinn, 2018) and for informing research and practice in the field of homelessness. According to this approach, human development should be measured by capabilities, that is, the freedoms that an individual has to be and to do in a specific context, along with the outcomes of embracing those freedoms, called functionings (Batterham, 2019; Nussbaum, 2001; Sen, 1992). Based on Sen's (2004) theorization,
Nussbaum (2011) proposed a list of 10 central capabilities, referring to the critical components of agency and freedom, but also including relationships with other living beings: life; bodily health; bodily integrity; affiliation; other species; play; senses, imagination, and thought; emotions; practical reason; and control over one's environment. Although the list is not exhaustive, it represents a base from which individuals can express themselves and live meaningful lives. In a capability-fostering service, activities are aimed at restoring users' capabilities by working on individual and contextual affordances, users are considered as resources and they are encouraged to participate in choices about their recovery (Greenwood et al., 2020a). Although this approach is gaining a critical role in guiding research and practice in the field of homelessness, few studies have empirically evaluated service efficacy by measuring users' capabilities (Greenwood et al., 2020b; O'Shaughnessy et al., 2020). To our knowledge, no studies investigated the association between capability-fostering services and providers' work experience and well-being. However, according to Maton's model (2008) a capability-fostering service has a greater potential to promote not only users' recovery, but also providers' well-being.

Identifying service features associated with providers' work engagement and burnout is critical in order to develop interventions aimed at improving the efficacy of homeless services, both in terms of users' outcomes and providers' well-being. To date, the small number of studies focused on evaluating the role of training and supervision in shaping the work experience of providers working in homeless services obtained mixed results, with some studies underscoring their crucial role for providers' work and well-being (e.g., Bride, 2004; Olivet et al., 2010) and others showing no association between training/supervision and providers' well-being (e.g., Lemieux-Cumberlege \& Taylor, 2019) or a different impact based on how these organizational practices are perceived by workers (ChoyBrown, Stanhope, Tiderington, \& Padgett, 2016). In addition, to our knowledge, no studies analyzed the degree to which a service promotes clients' capabilities as one of the service features that might be associated with providers' work experience. Finally, in the field of homeless research, only a few studies have been conducted in the European context and adopted a cross-national perspective (e.g., Greenwood, Stefancic, Tsemberis, \& BuschGeertsma, 2013).

Considering the potential detrimental consequences of low levels of work engagement and high levels of burnout, the current work aims at expanding the current literature by evaluating the association between the features of homeless services and providers' work experience. More specifically, the availability of training and supervision, 
the extent to which providers' perceive these activities as useful, and the degree to which the service fosters users' capabilities will be investigated in relation to providers' work engagement and burnout, in a sample of providers working in homeless services in eight European countries. Based on the theoretical framework and empirical evidence on PIE (Keats et al., 2012; Olivet et al., 2010), which emphasizes the role of training and supervision in supporting homeless service providers' work, and Maton's model of empowering community settings (Maton, 2008), underlining the importance of adopting a strength-based approach for providers' motivation and engagement (Gaboardi et al., 2019), we expect that staff training and supervision, along with a capability-fostering approach within the service, will be associated with higher levels of work engagement and lower levels of burnout.

\section{Method}

\section{Procedure}

The present study is part of the Horizon 2020 European project "Homelessness as Unfairness (HOME_EU)" and was conducted in eight European countries (France, Ireland, Italy, the Netherlands, Poland, Portugal, Spain, and Sweden). The lead consortium partner shared the research protocol among Consortium partners and obtained ethical approval from their organization/university's Ethical Committee. The protocol has also been approved by the European Ethics Committee (Ref. Ares (2017) 535021-31/01/ 2017).

Participants were recruited in organizations working with people experiencing homelessness in each country. Following the research protocol, each partner selected organizations located in different areas of the country; only providers with at least six months work experience in the organization were included in the study.

Data were collected through an online questionnaire (translated in eight different languages following detailed translation and back-translation procedures; Beaton, Bombardier, Guillemin, \& Ferraz, 2000) managed by the lead consortium partner from September 2018 to February 2019. Each national team received the link to the survey and proceeded with the recruitment of participants.

\section{Participants}

Overall, 770 providers working in homeless services were recruited in eight European countries. Although the research protocol for the study specified recruitment of social service providers working with adults experiencing homelessness, it is quite common for homeless services to work with multiple targets, such as unaccompanied foreign minors, and people with mental health problems regardless of their homeless situation. Thus, 169 providers who did not work specifically with people experiencing homelessness were not included in the present work. In addition, based on our research protocol, 26 participants who worked in the service for less than 6 months were excluded from the analyses.

After eliminating participants having missing values in some of the variables under study, the analyses were run on a final sample of 497 social service providers (62\% women; mean age $=40.7, S D=10.4)$. The distribution of the sample across countries is depicted in Table 1. The educational level of participants was quite high, with $80.9 \%$ of the sample reporting having completed a postsecondary school program (obtaining at least a bachelor degree), and working in the service for an average of 6.5 years $(S D=5.9)$. Participants reported working an average of 33.4 weekly hours in the service $(S D=9.5)$.

Measures

\section{Dependent Variables}

Work engagement (WE). The Utrecht Work Engagement Scale (UWES-9; Schaufeli, Bakker, \& Salanova, 2006) was used to measure providers' engagement with their work, that is, the degree to which they feel a sense of fulfillment characterized by vigor, dedication, and absorption. The scale is composed of nine items and the response categories ranged from (0) "never" to (6) "always" (sample items: "At my job, I feel strong and vigorous" and "I am enthusiastic about my job"). The scale showed good internal reliability $(\alpha=.90)$.

Burnout. Burnout was assessed through the Link Burnout Questionnaire (LBQ; Santinello et al., 2006), a 24item instrument designed to measure four different components of the burnout syndrome: psychophysical exhaustion (PE; e.g., "I feel under a lot of pressure at work"), relational deterioration (RD; e.g., "Most of my users do not follow my advice"), professional inefficacy (PI; e.g., "I feel incapable of facing my users' problems"), and disillusionment (DI; e.g., "My expectations as far as my job is concerned have been disappointed"; each subscale includes 8 items). Although the scale measures subdimensions of a single construct, the manual suggests to analyze the four components separately. Participants responded on a scale ranging from 0 (never) to 6 (everyday), and the subscales demonstrated acceptable internal reliability ( $\alpha=.66$ for PE, .64 for PI, .51 for RD, and .83 for DI). The LBQ was chosen because it is the only instrument including the subdimension "disillusionment," which is extremely relevant for care providers working with extreme marginalization (Pines \& Aronson, 1988). 
Table 1 Sociodemographic and professional characteristics of participants

\begin{tabular}{|c|c|c|c|c|c|c|c|c|c|}
\hline Characteristics & France & Ireland & Italy & Netherlands & Poland & Portugal & Spain & Sweden & Full sample \\
\hline $\begin{array}{l}\text { Number of } \\
\text { participants, } \\
n(\%)\end{array}$ & $54(10.9)$ & $31(6.2)$ & $117(23.5)$ & $94(18.9)$ & $117(23.5)$ & $39(7.8)$ & $31(6.2)$ & $14(2.8)$ & $497(100)$ \\
\hline Age, $M(S D)$ & $38.0(9.4)$ & $39.9(7.4)$ & $38.8(10.2)$ & 41.8 (11.7) & $42.8(10.6)$ & $40.1(10.1)$ & $39.5(9.9)$ & $48.8(8.6)$ & $40.7(10.4)$ \\
\hline Gender $(\mathrm{F}), n(\%)$ & $40(74.1)$ & $16(51.6)$ & $53(45.3)$ & $59(62.8)$ & $78(66.7)$ & $30(76.9)$ & $20(64.5)$ & $12(85.7)$ & $308(62.0)$ \\
\hline $\begin{array}{l}\text { Education } \\
\text { (Post-secondary } \\
\text { degree), } n(\%)\end{array}$ & $51(94.4)$ & $28(90.3)$ & $83(70.9)$ & $81(86.2)$ & $90(76.9)$ & 33 (84.6) & $30(96.8)$ & $6(42.9)$ & $402(80.9)$ \\
\hline $\begin{array}{c}\text { Weekly working } \\
\text { hours, } M(S D)\end{array}$ & $34.8(4.8)$ & $37.3(4.5)$ & $30.3(10.1)$ & $30.8(5.5)$ & $36.5(12.1)$ & $30.4(12.0)$ & $37.1(6.3)$ & $38.8(2.9)$ & $33.4(9.5)$ \\
\hline $\begin{array}{l}\text { Years in service, } \\
M(S D)\end{array}$ & $5.7(5.6)$ & $6.3(6.0)$ & $5.8(5.1)$ & $5.4(5.2)$ & $8.3(6.9)$ & $8.9(5.7)$ & $4.7(4.0)$ & $5.7(6.2)$ & $6.5(5.9)$ \\
\hline \multicolumn{10}{|c|}{ Training assessment, $n(\%)$} \\
\hline Not useful & $18(33.3)$ & $6(19.4)$ & $25(21.4)$ & $28(29.8)$ & $19(16.2)$ & $10(25.6)$ & $11(35.5)$ & $3(21.4)$ & $120(24.1)$ \\
\hline Useful & $27(50.0)$ & $23(74.2)$ & $79(67.5)$ & $64(68.1)$ & $47(40.2)$ & $20(51.3)$ & $17(54.8)$ & $5(35.7)$ & $282(56.7)$ \\
\hline \multicolumn{10}{|c|}{ Supervision assessment, $n(\%)$} \\
\hline Not useful & $8(14.8)$ & $7(22.6)$ & $14(12.0)$ & $15(16.0)$ & $12(10.3)$ & $5(12.8)$ & $9(29.0)$ & $1(7.1)$ & $71(14.3)$ \\
\hline Useful & $27(50.0)$ & $19(61.3)$ & $66(56.4)$ & $46(48.9)$ & $26(22.2)$ & $15(38.5)$ & $11(35.5)$ & $11(78.6)$ & $221(44.5)$ \\
\hline
\end{tabular}

\section{Independent Variables}

Staff training. A single item measured whether the service makes training available for the staff (yes/no). If participants replied affirmatively, they were asked to evaluate the degree to which the training is useful for their work, from 1 (very low usefulness) to 5 (very high usefulness). Then, the two items were integrated in order to create a 3-level single variable: 0 (no training); 1 (training evaluated as not useful); and 2 (training evaluated as useful). Two dummy variables were created so that it was possible to compare providers working in service where training (not useful and useful) is available to providers reporting no training within the service.

Staff psychosocial supervision. Participants were asked to report whether psychosocial supervision meetings are available for the service staff (yes/no). When they said yes, providers were also asked to evaluate the usefulness of the supervision for their work from 1 (very low usefulness) to 5 (very high usefulness). Responses from the two items were then integrated in a 3-level single variable: 0 (no supervision) ; 1 (supervision evaluated as not useful); and 2 (supervision evaluated as useful). Two dummy variables were created in order to compare providers working in service where supervision (not useful and useful) is available to providers reporting that supervision for the staff is not available within the service.

Capability-fostering service. A 10-item scale was employed to measure the degree to which participants perceived that their service is fostering clients' capabilities. The scale represents a shorter version of the Capabilities Questionnaire for the Homeless Services Context (Sacchetto et al., 2018), which has been adapted for providers. One item has been selected for each of the
10 capabilities, and providers were asked to indicate the degree to which their service promotes each capability on a scale ranging from 1 (completely disagree) to 5 (completely agree; e.g., "Through this service, a user is able to have more control over decisions that affect one's life"). A single score was obtained by averaging the scores of the ten items reflecting the ten capabilities. The scale showed good internal reliability $(\alpha=.88)$.

Individual professional and demographic variables. Participants also reported their age, gender, and educational level: $1=$ middle school (completed); 2 = high school/secondary school (completed); $3=$ posthigh/secondary school course (not completed); and $4=$ degree programs/completed post-secondary school (bachelor's or master's degree, doctoral degree, $\mathrm{PhD}$, vocational training). Since most providers engaged in the study reported to have obtained a post-secondary degree $(80.6 \%)$, a dichotomous variable was created $(0=$ postsecondary programs not completed; $1=$ post-secondary degree). Although participants who completed a postsecondary degree were also asked to report the area of their post-secondary education, only 289 (out of 402) participants reported their degree course; thus, this variable was not included in the analysis. In order to control for professional variables that showed their association to providers' well-being, participants indicated the formal number of working hours per week (as stated in their contract) and how long they have been working in the service (in years).

\section{Analytic Strategy}

Since study data were inherently clustered, with social service providers coming from eight different countries, 
we used the multilevel regression technique of hierarchical linear modeling with providers nested within countries (HLM; Raudenbush \& Bryk, 2002). We did not have hypotheses in relation to country-level characteristics (and the number of countries was insufficient to test hypotheses at the second level; see Maas \& Hox, 2005). Nevertheless, it seemed plausible participants from the same nation may be more similar to one another (in relation to our dependent variables) than participants from other countries.

For this reason, we checked whether our dependent variables varied by country; since a significant portion of the variance lay at the country level, a random effect for country was included in the equation. Thus, five independent random coefficient models (one for each dependent variable) were run, controlling for the random effect of country. These models estimate the association within countries of training, supervision, and capabilities fostering service with the dependent measure of providers' work engagement, psychophysical exhaustion, professional inefficacy, relational deterioration, and disillusionment for provider $i$ in country $j$, controlling for age, gender, education, weekly working hours, and years in the service.

The random coefficient models include five predictors and five control variables:

$\mathrm{WE} / \mathrm{PE} / \mathrm{PI} / \mathrm{RD} / \mathrm{DI}_{i j}=\gamma_{00}+\gamma_{10}($ age $)+\gamma_{20}($ gender $)+$ $\gamma_{30}$ (post-secondary degree) $+\gamma_{40}$ (weekly hours) $+\gamma_{50}$ (years in service) $+\gamma_{60}$ (training not useful $)+\gamma_{70}$ (training useful $)+\gamma_{80}$ (supervision not useful) $+\gamma_{90}$ (supervision useful $)+\gamma_{100}$ (capabilities fostering service $)+u_{0 j}+r_{i j}$.

\section{Results}

\section{Descriptive Statistics}

Descriptive statistics for the variables under study are shown in Table 2. There was a wide variation both in providers' work engagement and burnout scores, with standard deviations ranging from 4.09 to 5.53 in burnout subscales and a standard deviation of .89 in work engagement. Almost 20\% of participants reported that there was no training available in their service. More than a half of providers reported participating in trainings perceived as useful for their everyday work, while about one quarter of them reported that the training provided by their service is not useful. More than $40 \%$ of social service providers reported that supervision activities were not provided in the service where they work, $44 \%$ felt that supervision activities supported their work, while $14 \%$ found the supervision within the service was not helpful.
A preliminary step in HLM consists in fitting an unconditional model and estimating the variance of the dependent variables, partitioning them into individual- and country-level components. Country accounted for a significant portion of variance for each dependent variable: $2.28 \%$ for work engagement, $7.18 \%$ for emotional exhaustion, $9.56 \%$ for professional inefficacy, $18.60 \%$ for relational deterioration, and $6.02 \%$ for disillusionment. Although the estimated country-level variances of the dependent variables are statistically significant (respectively: $\chi_{(7)}^{2}=18.15, \quad p<.05 ; \chi_{(7)}^{2}=35.48, \quad p<.001$; $\chi_{(7)}^{2}=63.07, \quad p<.001 ; \quad \chi_{(7)}^{2}=104.45, \quad p<.001 ;$ $\left.\chi_{(7)}^{2}=37.63, p<.001\right)$, there was a greater variability between individuals within countries than individuals between countries. The estimated reliability with which countries can be distinguished on the dependent variables varied from .53 in work engagement to .90 in relational deterioration.

Evaluation of the Research Hypotheses

The HLM models predicting each of the dependent variables measuring providers' work experience and well-being are depicted in Table 3. Overall, our findings show that working in a service adopting a capability approach was associated with all the providers' outcomes under study (higher engagement and lower burnout), the availability of staff training was associated with providers' well-being (higher engagement and lower professional inefficacy, but only when the training was considered useful), while supervision was not associated with higher levels of providers' well-being (in fact, when perceived as not useful, it was positively associated with burnout).

The first model, having work engagement as dependent variable, shows that providers reporting to work in a service where useful training for the staff is available were also more engaged in their work activities than their counterparts working in services without any staff training $(\beta=0.20, S E=0.10, t=1.96, p=.05)$. Moreover, a

Table 2 Descriptive statistics and psychometric properties for work engagement, burnout and capability-fostering approach

\begin{tabular}{lcccc}
\hline \multicolumn{1}{c}{ Variable } & $M$ & $S D$ & Range & Cronbach's $\alpha$ \\
\hline Work engagement (UWES-9) & 4.32 & 0.89 & $0-6$ & .90 \\
Burnout (LBQ) & & & & \\
$\quad$ Psychophysical exhaustion & 17.81 & 4.85 & $6-36$ & .66 \\
$\quad$ Professional inefficacy & 13.64 & 4.09 & $6-36$ & .64 \\
$\quad$ Relational deterioration & 17.22 & 4.42 & $6-36$ & .51 \\
$\quad$ Disillusionment & 12.82 & 5.53 & $6-36$ & .83 \\
Clients' capability- & 3.87 & 0.70 & $1-5$ & .88 \\
$\quad$ fostering service & & & & \\
\hline
\end{tabular}

Note. LBQ = Link Burnout Questionnaire, UWES-9 = The Utrecht Work Engagement Scale. 


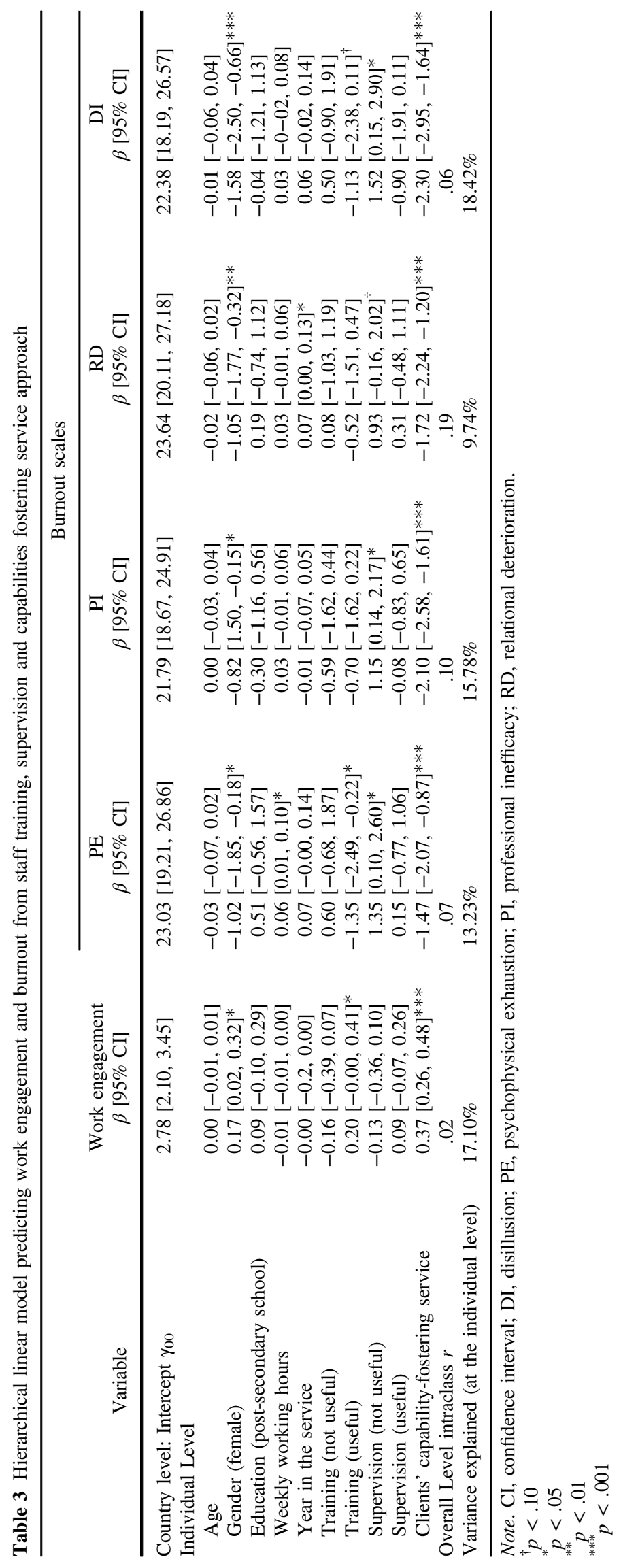


positive association was found between the degree to which providers feel that their service is promoting clients' capabilities and work engagement $(\beta=0.37, S E=0.05, t=6.74$, $p<.001)$. No associations were found between providers' work engagement and training that was evaluated as not useful, and between work engagement and supervision.

The second model shows a negative association between reporting the availability of useful trainings and $\mathrm{PE}$ (one of the four components of burnout), that is, providers working in services providing training that is helpful for their work, also reported less emotionally exhaustion compared to professionals working in services where no training is provided $(\beta=-1.35, S E=0.58$, $t=-2.34, \quad p<.05)$. Consistently with the previous model, having trainings available within the service, but feeling that they are not useful, was not associated with psychophysical exhaustion. Instead, emotional exhaustion was positively associated with the availability of psychosocial supervision meetings, when providers judged that supervision was not supporting their work $(\beta=1.35$, $S E=0.64, t=2.12, p<.05)$. No association was found between useful supervision and exhaustion, while PE was negatively associated with the evaluation of the service as capability fostering $(\beta=-1.47, S E=0.30, t=-4.83$, $p<.001)$. Finally, providers reporting a higher amount of weekly working hours were also more emotionally exhausted $(\beta=0.06, S E=0.10, t=2.49, p<.05)$. PI was also positively predicted by the availability of supervision not useful for the work of the staff $(\beta=1.15, S E=$ $0.51, t=2.24, p<.05$ ), while no associations were found with useful supervision and training (useful or not useful). Once again, working in a service promoting clients' capabilities was negatively associated with the feeling of professional inefficacy $(\beta=-2.10, S E=0.25$, $t=-8.52, p<.001)$. The third dimension of burnout, that is, the RD with clients, was also negatively predicted by providers' belief that the service is promoting capabilities $(\beta=-1.72, S E=0.26, t=-6.48, p<.001)$. A marginal positive association was found between the availability of supervision judged as not useful and RD ( $\beta=0.93, S E=0.55, t=1.68, p<.10)$. In addition, providers with a longer work experience in the service also reported higher levels of relational deterioration with clients $(\beta=0.07, S E=0.03, t=2.13, p<.05)$. In the last model, consistently with the previous ones, a positive association was found between working in a service providing supervision that providers evaluate as not useful and the feeling of DI $(\beta=1.52, S E=0.70, t=2.17$, $p<.05$ ), while working in a capability promoting service was negatively related to providers' DI about their job $(\beta=-2.30, S E=0.33, t=-6.87, p<.001)$. A marginal negative association $(p>.10)$ was also observed between the availability of useful trainings in the service and providers' levels of DI $(\beta=-1.13, S E=0.63, t=1.78$, $p<.10$ ), while no association was found when the training provided to staff was judged as not useful.

In relation to demographic variables, only gender was associated with providers' well-being: indeed, women reported higher levels of work engagement $(\beta=0.17$, $S E=0.08, \quad t=2.27, \quad p<.05 ; \quad \beta=.20, \quad S E=0.10$, $t=1.96, p=.05$ and lower levels of burnout, especially in relation to deterioration of the relationship and disillusionment; $\beta=-1.01, S E=0.42, t=-2.40, p<.05$ for psychophysical exhaustion; $\beta=-0.82, \quad S E=0.34$, $t=-2.40, p<.05$ for professional inefficacy; $\beta=-1.05$, $S E=0.37, t=-2.83, p<.01$ for relational deterioration; $\beta=-1.58, S E=0.472, t=-3.39, p<.001$ for disillusionment).

Considering the wide variety of individual and contextual factors that can influence service providers' well-being, the models explained a fair amount of variance in the dependent variables. The models explained about $18 \%$ of the variance in providers' disillusionment, $17 \%$ in work engagement, $15 \%$ in professional inefficacy, $13 \%$ in psychosocial exhaustion, and 9\% in relational deterioration.

\section{Discussion}

The main aim of this study was to identify the factors protecting homeless service providers from developing burnout symptoms and promoting a positive working experience. Considering the complexity of service users' needs and the contextual challenges of working with extremely marginalized populations (Kulkarni et al., 2013; Lemieux-Cumberlege \& Taylor, 2019; Lewer et al., 2019), our aim was to determine whether training, supervision, and a capability-fostering approach were associated with higher levels of work engagement and lower levels of burnout in a cross-national sample of providers working in homeless services. Overall, our findings partly confirmed our hypotheses, showing the role of training and supervision in shaping providers' work experience. However, results varied depending on whether providers thought that the training and supervision experiences provided within the services were useful for their work and based on the specific outcome considered (work engagement or the different components of burnout).

\section{Professional Training and Providers' Work Engagement and Burnout}

In general, our findings showed that staff training, when perceived relevant for the work, is associated with providers' well-being, while no association was found when training was perceived as not useful by providers. More 
specifically, working in a service where training is available for staff is associated with higher levels of providers' work engagement and lower levels of two dimensions of burnout: psychophysical exhaustion and disillusionment. In line with scholars identifying the availability of trainings as one of the main features of PIE (Keats et al., 2012), our results pointed out the importance of training for providers' feeling of engagement in the work activities and goals. However, the availability of professional training seemed to have a positive effect on providers' work experience only when providers reported that the trainings organized within their services were useful. These findings can be understood in light of the complex array of competencies and knowledge required for working with extremely marginalized populations; indeed, users' challenging clinical picture, their difficult relationship with care providers, and the organizational and contextual challenges characterizing homeless services might be hard to address without constantly learning innovative and evidence-based strategies. These results are also in line with a study showing the importance of training to face staffing challenges in the field of homeless services (Olivet et al., 2010). According to our findings, the availability of useful training for the staff corresponds to stronger feelings of involvement, dedication, and absorption in work activities and goals. It is possible that the opportunity to learn new skills make providers more capable of understanding the rationale for the interventions carried out within the service and the relation between vision, activities, and goals; this can in turn make them more engaged in their everyday work, since they feel they are contributing to reach those goals (Gaboardi et al., 2019). This can be said also for work activities not directly related to users' recovery, such as networking and political activities. It is worth noting that, although the positive impact of working with clear and realizable goals might occur regardless of goal content, prioritizing specific goals (e.g., adopting a recovery oriented approach) and transmitting them through training might be particularly beneficial. Future research should also take into account how setting specific goals within services might impact providers' well-being and work engagement. Also, in services where activities are not well-organized or motivated by a clear rationale, having the opportunity to acquire new knowledge and skills through professional training may help providers feeling competent to improve service activities, for example, by finding alternative strategies and approaches.

According to our findings, providers attending trainings supporting their daily work had fewer feelings of psychosocial exhaustion and disillusionment. Acquiring knowledge and competencies in one's working area may make it more likely to reach service goals. Having the chance to see the results of their work might nurture providers' sense of efficacy and reduce the feelings of tiredness. Indeed, providers might experience feelings of powerlessness and depression when working without clear and realizable goals, and unrealistically lofty goals may increase disappointment and burnout (Fisk, Rakfeldt, \& Heffernan, 1999). In a similar vein, providers working in services where useful training was available also reported lower levels of disillusionment: when the acquisition of competencies facilitates the achievement of service goals with clients, providers might be less exposed to the feelings of disillusionment deriving from the discrepancy between expectations and reality. Indeed, the availability of trainings matching providers' formative needs (i.e., evaluated as "useful" by them) in a particular service, by making work activities more effective, can reduce the gap between idealistic principles and everyday practice (Fisk et al., 1999), thus decreasing their levels of disillusionment. It is also possible that, for providers, having the chance to learn new skills and abilities is associated with the perception of prestige for their professional role, which could prevent the development of feelings of disillusionment deriving from a discrepancy between job expectations and the reality of the profession (Santinello et al., 2006). However, only a marginal association was found between staff training and disillusionment, and the findings have to be interpreted with caution. Staff training might also include organizational skills favoring a more efficient organization of work activities, conserving providers' physical and emotional energy, thus reducing the likelihood of feeling exhausted. In addition, as shown by the literature analyzing the benefits of PIE in homeless services, thanks to the training received, providers might improve their capacity to recognize early signs of physical and emotional tiredness (Hopper, Bassuk, \& Olivet, 2009); as a consequence, they might be more able to search for and identify an effective solution to their symptoms of exhaustion. In general, our findings underline that, compared to homeless services without a training program for their staff, organizations where relevant training is available to providers appear beneficial for their work engagement and protective against burnout; either having no training at all, or receiving training that is perceived as not useful, might represent a missed opportunity to nurture providers' engagement in their work and prevent psychophysical exhaustion and disillusionment.

Given the correlational design of our study, however, we must acknowledge that individuals with high levels of professional engagement and efficacy might seek information about the training offered in different organizations and apply to organizations that have a good training plan for the staff; this would allow them to consolidate both their already strong involvement and perceived efficacy at work. In addition, services providing training for the staff 
might differ from other organizations in relation to management policies which may impact organizational climate and staff well-being. Finally, no association was found between staff training perceived as not useful and providers' work engagement and burnout. It is worth noting that, according to our findings, irrelevant training does not promote providers' well-being, but does not seem to constitute a risk factor either; it is possible that for service providers, receiving training that is not directly related to their daily work activities is not increasing their risk of burnout because they might see the value of the acquired knowledge and skills in relation to future professional roles.

\section{Psychosocial Supervision and Providers' Work Engagement and Burnout}

Unexpectedly, in relation to the availability of psychosocial supervision, our results showed no association between the availability of supervision within the service and providers' burnout and work engagement, when it was perceived as useful. Psychosocial supervision was associated with increased burnout symptoms when providers reported that this activity was not useful for their everyday work. In particular, reporting that the service is offering non-useful supervision was positively related to feelings of disillusionment, psychophysical exhaustion, and professional inefficacy. In other words, supervision seemed to be a risk factor for the development of burnout symptoms in providers, when this activity is not considered useful. Although these findings were not expected and have to be interpreted with caution, psychosocial supervision is a very complex and sensitive activity and its effects can vary widely based on the quality and adequacy of the proposed activities.

Several reasons might motivate providers' evaluation of supervision as not useful for their work and explain its association with providers' burnout and reduced work engagement. In the literature on service providers' experiences, providers report being berated by supervisors, questioning supervisor's competence, or being reluctant to share the problematic aspects of their experiences at work (Choy-Brown et al., 2016; Cook, Welfare, \& Romero, 2018; Ellis et al., 2014). Concerns about the usefulness of supervision might also derive from a judgmental climate, failure to address the most pressing issues of the service, or providers' perception that supervision is not really necessary in their service (Cook et al., 2018). Also, supervision with a strong focus on problems and crisis situations, if not balanced by a strength-based approach aimed at identifying staff and organizational resources, may not be effective. As shown in the literature, these factors are not only a potential waste of time, in a field where excessive workload is very common for staff, but also a hazard for providers' well-being and quality of care. Unlike what we observed with training, which may still be beneficial irrespective of its relevance for the role (thus explaining the lack of association between staff training evaluated as not useful and providers' well-being), supervision perceived as not useful might be detrimental in several ways; for example, a supervision creating a judgmental climate or focused on berating providers might have a negative impact on the relationships among the staff members and reduce providers' effort and engagement. However, we need to take into account that providers experiencing burnout symptoms might also have a worse perception of the supervision offered by the service, other organizational features and the workplace in general. It is possible that providers who developed high levels of exhaustion, professional inefficacy, and disillusionment (as a consequence of a combination of individual, relational and organizational factors) gave more negative evaluations to the supervision available in the service, regardless of its actual quality. Supervision refers to all the structures (and related activities) creating an environment where service staff can develop themselves and contribute to the development of other staff members (Neil, Nothard, Glentworth, \& Stewart, 2010). Although various type of psychosocial supervision exist, such as individual, group, peer, informal support, and ad hoc consultancy (Durham, Swan, \& Fisher, 2000), key common aspects of psychosocial supervision include review and reflection on one's own work; reflective and case review activities allow providers to process their work experiences with colleagues and identify alternative ways to take care of service users (Cockersell, 2011). When these activities meet the providers' needs within a service, by giving them the chance to reflect on and improve key problematic components of the work experience within a particular service, they might nurture providers' work engagement and protect them from burnout (Leiter \& Maslach, 2006). However, our findings did not show any differences in work engagement and burnout between providers working in homeless services offering useful supervision activities compared to providers working in services not offering any kind of supervision to staff. These findings are in line with Lemieux-Cumberledge and Taylor's (2019) study, where the authors found no relation between different forms of supervision and organizational support and providers' psychological distress. Both our and Lemieux-Cumberledge's findings could be explained by the variety of types of supervision offered to providers, which might be associated with different components of providers' well-being not captured by our outcome variables (e.g., motivation, job satisfaction, or social cohesion among the staff members). In addition, the definition of useful supervision 
might be more open to subjective interpretations by providers than "useful training;" while for the latter providers are asked to evaluate the usefulness of a process of acquisition of new knowledge and skills, the variety of types of psychosocial supervision might have made the interpretation of its usefulness very heterogeneous and based on different criteria (e.g., the degree to which supervision is lowering the workload or promoting social cohesion within the team). It is also possible that supervision is interacting with other providers' characteristics in influencing different aspects of providers' well-being, having differential effects on providers with different demographic profile or work experience. Future studies should analyze the types of supervision that providers do and do not find useful depending on their age and professional experience, which may offer an explanation for the contradictory findings in relation to providers' age and professional experience (Kulkarni et al., 2013; Salloum et al., 2015; VanDeusen \& Way, 2006).

\section{Capability-Fostering Services and Providers' Work Engagement and Burnout}

The most consistent finding of the current study was the association between a capability-fostering service delivery approach (i.e., promoting users' opportunities to restore their freedom to choose and realize their life goals) and providers' well-being. According to our findings, providers who perceived that the service has the potential to and will promote clients' capabilities also reported higher levels of involvement in work activities and goals and lower levels of psychophysical exhaustion, relational deterioration, professional inefficacy, and disillusionment (the four components of the burnout syndrome). The degree to which the service adopts a capability-fostering approach was the only feature that showed an association with all the aspects of providers' work experience and well-being analyzed. Moreover, its role in promoting work engagement and reducing burnout seemed stronger compared to supervision and training, underlying the importance of adopting a capabilities framework in homeless services to support providers' work engagement and protect them from burnout symptoms. These findings can be interpreted in light of Maton's model of empowering community settings (Maton, 2008), according to which a homeless service characterized by a strength-based approach can promote empowerment both in users and providers; this might be reflected in higher engagement and lower levels of stress among the staff. This is particularly true when dealing with homelessness, which can be considered as a situation of extreme inequality deriving from capabilities deprivation or failure (Batterham, 2019). When working at promoting users' capabilities, then, there is a consistency between idealistic principles and work practices aimed at restoring a situation of equality in the development of capabilities. Perceiving that their daily work is effective and contributing to a larger purpose can be extremely motivating, and nurture providers' work engagement by simultaneously protecting them from stress and burnout (Fisk et al., 1999). The chance to see the positive results of one's own work in terms of users' capabilities can also nurture the feeling of "compassion satisfaction", that is, the sense of fulfillment associated with giving effective support to people who are suffering (Wagaman et al., 2015).

It is worth noting that we measured the degree to which the service promotes user's capabilities from the point of view of service providers. Thus, our findings suggest that it is critical for program leaders not only to base service activities on this approach, but also to be intentional about communicating with the staff that the capability approach represents a conscious philosophy of the program. It would be important to be explicit in this approach starting from the hiring process (which might also take into account the affinity between personal and organizational values in the selection), so that providers' work can be guided by values they share and well-defined goals.

For example, being aware of the specific capabilities and functionings that the service aims to promote in users (e.g., finding a job) might make it easier to identify individual attributes and characteristics supporting or hindering these capabilities (such as motivation), as well as contextual constraints and resources (such as the availability of professional training in the community). A clear strength-based approach might also make it easier for providers to see whether the goals set for each service user have been reached, and this can have positive consequences for their motivation. In sum, perceiving that thanks to the service, users can develop their capabilities appeared to be a key ingredient for providers' sense of fulfillment and satisfaction at work. The consistency and strength of the association between the capability-fostering approach and providers' well-being might lie in providers' perception that the service is not only solving problems or having a general positive impact on users' life; instead, they perceive that the service activities are helping users' in choosing new paths in several domains of their lives. However, given the correlational nature of the study, it is possible that the association between the capability-fostering approach and providers' well-being is either due to reverse causation or confounded by a third variable. Indeed, a self-selection process might make it more likely for individuals with capability-oriented values to seek employment in organizations adopting a strength-based approach, and their values protect them from burnout; 
alternatively, homeless services adopting a capability-fostering approach might prefer hiring individuals showing high engagement in their work. Finally, capability-fostering services might also adopt policies aimed at promoting staff well-being and engagement. It is possible that the organizational features analyzed (training, supervision, capability-fostering approach) and providers' well-being are characterized by a complex, bidirectional association. In relation to demographic variables, only gender was associated with providers' well-being and work experience, with women reporting higher levels of work engagement and lower levels of burnout (especially in relation to professional inefficacy and disillusionment). This is partly in contrast with past literature, generally labeling burnout as a female experience (Maslach et al., 2001). However, a meta-analysis (Purvanova \& Muros, 2007) showed that men and women tend to experience burnout in a different way, with women more exposed to emotional exhaustion (different from our findings) and men experiencing more relational deterioration (in line with our findings).

Taken altogether, our findings showed that in homeless services, providers' work engagement and burnout are associated with organizational characteristics of the service, namely training, supervision and a capability-fostering approach.

\section{Study Limitations}

The current work has some limitations that need to be considered. First, this study is cross-sectional, with both predictors and outcome variables measured at the same point in time, and making causal inferences is impossible. Future longitudinal studies examining how organizational characteristics predict providers' work engagement and burnout at a second point in time are needed in order to address this limitation. In addition, all the measures used in the study were self-reported; this approach is vulnerable to same-source and social desirability bias. To address this limitation and further our findings, future research could collect data on service characteristics from other sources (such as service coordinators and users). In particular, judgments of the usefulness of training and supervision could be colored by burnout. In addition, the internal consistency of the burnout subscale "relational deterioration" was low as compared to the validation study of the instrument (Santinello et al., 2006). It is possible that, although we followed detailed translation and back-translation procedures (Beaton et al., 2000), the multiple language translation has affected the internal consistency of this subscale.

Another limitation of this work has to do with the sample: although all the research teams followed the same recruiting strategies described in the protocol, there was wide variation in the final size of the national samples. For this reason, we chose to control for the random effect of country without analyzing potential predictors at the country level. The best analytic strategy for our study hypotheses would have been nesting participants within services, thus being able to compute aggregate scores of service characteristics within agencies. Unfortunately, in our sample the majority of services (191 out of 283) were represented by a single provider, thus making the aggregation of service features scores impossible. Future research measuring both individual perceptions and aggregate scores is needed, since it is possible that both subjective perceptions and aggregate scores of service features have a role in shaping providers' well-being (and this analytic strategy would allow to differentiate the two effects). Furthermore, we did not differentiate between types of training and supervision approaches, which can vary widely across services and national context. However, considering the cross-national nature of the sample and the inclusion of providers coming from many different services (and the wide variation in training and supervision approaches deriving from this), we chose not to measure training and supervision approaches. This choice might have affected our findings on training and especially on supervision, since the variety of supervision types and approaches was not taken into account. Also, the reasons underlying the evaluation of training and supervision activities as useful or not useful were not investigated; instead, we preferred to rely on the subjective perception of providers (since the usefulness can vary a lot across services, professional roles, country, educational background etc.). Future research should focus on the specific characteristics of training and supervision associated with the well-being of providers, with the aim of understanding, for example, which specific styles and activities are associated with improvements in organizational climate, social cohesion, teamwork or problem-solving abilities; mixed method approaches, integrating quantitative and qualitative research, could also be helpful in understanding what is making training and supervision "useful" from the point of view of providers and the reason why activities perceived as useful are not associated with providers' well-being.

\section{Conclusions and Recommendations for Policy}

Notwithstanding these limitations, this is the first study adopting a cross-national approach aimed at identifying factors associated with providers' well-being in services working with people experiencing homelessness. More specifically, our findings showed the importance of training, supervision, and a capability-fostering approach in predicting providers' work engagement and burnout in 
eight countries, across multiple economic, social and political contexts. To our knowledge, this is also the first study evaluating whether the degree to which providers feel that the training and supervision provided within the service are useful is associated with their working experience and well-being. Overall, the availability of useful trainings for staff was a key factor both for promoting work engagement and protecting from burnout symptoms. On the contrary, when the training provided was considered not useful by providers, no association was found between training and providers' well-being. In light of this lack of association, and considering the limited resources characterizing services working with extreme marginalization, program leaders and policy makers should carefully consider the expected benefits of a particular training and its fit with the characteristics of the staff, for example, by asking providers for regular feedback. An even more careful approach should be used in relation to supervision: reflective activities give providers the opportunity to process their work with colleagues and find more effective strategies to support service users or take care of their own well-being, but this is not always the case. Indeed, there are studies where providers described negative experiences of supervision, for example, deriving from a lack of competence of the supervisor (Cook et al., 2018; Ellis et al., 2014) or feeling the supervision as a scrutiny of their work (Choy-Brown et al., 2016). This might explain our findings showing the positive association between being involved in non-useful supervision and burnout symptoms, especially in relation to feelings of disillusionment, psychophysical exhaustion, and professional inefficacy. Training and supervision are generally key components of PIE (Keats et al., 2012), recognizing how users' psychological needs and the complexity of the job can affect providers' well-being. However, homeless services should take into account that having these activities available within the service is not enough: they also need to be accurately planned and tailored to the needs and resources of providers.

Finally, our findings underlined the importance of adopting a strength-based approach, that is, a capabilityfostering approach, for promoting providers' work engagement and protecting them from burnout symptoms. A focus on strengths and resources should be adopted in services working with extreme marginalization in order to promote providers' well-being and, as a consequence, the quality of care.

Acknowledgments We thank the homeless service providers and their organizations for their participation in this research and the HOME_EU study group for the national data gathering and the cultural adaptation of materials. We also thank Martín Julián for collaborating in the study as Research Assistant. This work is supported by the European Commission through a grant, as part of H2020 research project HOME_EU: Reversing Homelessness in Europe H2020-SC6-REVINEQUAL-2016/ GA726997.

\section{References}

Adams, R. E., Boscarino, J. A., \& Figley, C. R. (2006). Compassion fatigue and psychological distress among social workers: A validation study. American Journal of Orthopsychiatry, 76, 103-108.

Aldridge, R. W., Story, A., Hwang, S. W., Nordentoft, M., Luchenski, S. A., Hartwell, G., .. \& \& Hayward, A. C. (2018). Morbidity and mortality in homeless individuals, prisoners, sex workers, and individuals with substance use disorders in highincome countries: A systematic review and meta-analysis. The Lancet, 391, 241-250.

Archard, P. J., \& Murphy, D. (2015). A practice research study concerning homeless service user involvement with a programme of social support work delivered in a specialized psychological trauma service. Journal of Psychiatric and Mental Health Nursing, 22, 360-370.

Baird, K., \& Kracen, A. C. (2006). Vicarious traumatization and secondary traumatic stress: A research synthesis. Counselling Psychology Quarterly, 19, 181-188.

Bakker, A. B., Albrecht, S. L., \& Leiter, M. P. (2011). Key questions regarding work engagement. European Journal of Work and Organizational Psychology, 20, 4-28.

Batterham, D. (2019). New theoretical directions: The capabilities approach and its application to homelessness. Parity, 32, 13.

Beaton, D. E., Bombardier, C., Guillemin, F., \& Ferraz, M. B. (2000). Guidelines for the process of cross-cultural adaptation of self-report measures. Spine, 25, 3186-3191.

Beijer, U., Bruce, D., \& Burström, B. (2016). Changes over time in the risk of hospitalisation for physical diseases among homeless men and women in Stockholm? A comparison of two cohorts. Scandinavian Journal of Public Health, 44, 784-790.

Bell, H., Kulkarni, S., \& Dalton, L. (2003). Organizational prevention of vicarious trauma. Families in Society: the Journal of Contemporary Social Services, 84, 463-470.

Berzoff, J., \& Kita, E. (2010). Compassion fatigue and countertransference: Two different concepts. Clinical Social Work Journal, 38, 341-349.

Bride, B. E. (2004). The impact of providing psychosocial services to traumatized populations. Stress, Trauma, and Crisis, 7, $29-46$.

Choy-Brown, M., Stanhope, V., Tiderington, E., \& Padgett, D. K. (2016). Unpacking clinical supervision in transitional and permanent supportive housing: Scrutiny or support? Administration and Policy in Mental Health and Mental Health Services Research, 43, 546-554.

Cockersell, P. (2011). More for less? Using PIEs and recovery to improve efficiency in supported housing. Housing, Care and Support, 14, 45-50.

Conrad, D., \& Kellar-Guenther, Y. (2006). Compassion fatigue, burnout, and compassion satisfaction among Colorado child protection workers. Child Abuse and Neglect, 30, 1071-1080.

Cook, R. M., Welfare, L. E., \& Romero, D. E. (2018). Counselorin-training intentional nondisclosure in onsite supervision: A content analysis. Professional Counselor, 8, 115-130.

Cornes, M., Manthorpe, J., Hennessy, C., \& Anderson, S. (2013). Little miracles: Using communities of practice to improve front line collaborative responses to multiple needs and exclusions. London: Revolving Doors Agency and King's College London.

Craig, C., \& Sprang, G. (2010). Compassion satisfaction, compassion fatigue, and burnout in a national sample of trauma treatment therapists. Anxiety, Stress, and Coping, 23, 319-339. 
Deck, S. M., \& Platt, P. A. (2015). Homelessness is traumatic: Abuse, victimization, and trauma histories of homeless men. Journal of Aggression, Maltreatment and Trauma, 24, 1022-1043.

Durham, R., Swan, J., \& Fisher, P. (2000). Complexity and collaboration in routine practice of CBT: What doesn't work so well and how might it work better? Journal of Mental Health, 9, 429-444.

Ellis, M. V., Berger, L., Hanus, A. E., Ayala, E. E., Swords, B. A., $\&$ Siembor, M. (2014). Inadequate and harmful clinical supervision: Testing a revised framework and assessing occurrence. The Counseling Psychologist, 42, 434-472.

Figley, C. R. (2002). Compassion fatigue: Psychotherapists' chronic lack of self-care. Journal of Clinical Psychology, 58, 1433-1441.

Fisk, D., Rakfeldt, J., \& Heffernan, K. (1999). Outreach workers' experiences in a homeless outreach project: Issues of boundaries, ethics, and staff safety. Psychiatric Quartely, 70, 231-246.

Gaboardi, M., Lenzi, M., Disperati, F., Santinello, M., Vieno, A., Tinland, A., ... \& Bokszczanin, A. (2019). Goals and principles of providers working with people experiencing homelessness: A comparison between housing first and traditional staircase services in eight European countries. International Journal of Environmental Research and Public Health, 16, 1590.

Geoffrion, S., Morselli, C., \& Guay, S. (2016). Rethinking compassion fa- tigue through the lens of professional identity: The case of child-protection workers. Trauma, Violence, and Abuse, 17, 270-283.

Greenwood, R. M., Manning, R. M., O’Shaughnessy, B. R., VargasMoniz, M. J., Auquier, P., Lenzi, M., ... \& The HOME_EU Consortium Study Group (2020a). Experiences of Homeless Services as Capabilities-Enhancing in Housing First versus Traditional Services: The Mediating Roles of Consumer Choice and Housing Quality. Unpublished manuscript. University of Limerick.

Greenwood, R. M., Manning, R. M., O’Shaughnessy, B. R., VargasMoniz, M. J., Loubiere, S., Spinnewijn, F., ... \& Ornelas, J. (2020b). Homeless adults' recovery experiences in housing first and traditional services programs in seven European countries. American Journal of Community Psychology, 65, 353-368.

Greenwood, R. M., Stefancic, A., Tsemberis, S., \& Busch-Geertsma, V. (2013). Implementations of Housing First in Europe: Challenges in maintaining model fidelity. American Journal of Psychiatric Rehabilitation, 16, 290-312.

Guglielmi, D., Avanzi, L., Chiesa, R., Mariani, M. G., Bruni, I., \& Depolo, M. (2016). Positive aging in demanding workplaces: The gain cycle between job satisfaction and work engagement. Frontiers in Psychology, 7, 1224.

Hensel, J. M., Ruiz, C., Finney, C., \& Dewa, C. S. (2015). Metaanalysis of risk factors for secondary traumatic stress in therapeutic work with trauma victims. Journal of Traumatic Stress, 28, 83-91.

Henwood, B. F., Shinn, M., Tsemberis, S., \& Padgett, D. K. (2013). Examining provider perspectives within Housing First and traditional programs. American Journal of Psychiatric Rehabilitation, 16, 262-274.

Hopper, E. K., Bassuk, E. L., \& Olivet, J. (2009). Shelter from the storm: Trauma-informed care in homelessness services settings. The Open Health Services and Policy Journal, 2, 131-151.

Kanste, O. (2011). Work engagement, work commitment and their association with well-being in health care. Scandinavian Journal of Caring Sciences, 25, 754-761.

Keats, H., Maguire, N., Johnson, R., \& Cockersell, P. (2012). Psychologically informed services for homeless people: Good practice guide. Southampton, UK: Department for Communities and Local Government. Available from: https://eprints.soton.ac. uk/340022/1/Good\%2520practice\%2520guide $\% 2520-\% 2520 \%$ 2520Psychologically\%2520informed $\% 2520$ services $\% 2520$ for $\%$ 2520homeless\%2520people\%2520.pdf [last accessed September 15 2020].

Kim, H., Ji, J., \& Kao, D. (2011). Burnout and physical health among social workers: A three-year longitudinal study. Social Work, 56, 258-268.

Knight, C. (2013). Indirect trauma: Implications for self-care, supervision, the organization, and the academic institution. The Clinical Supervisor, 32, 224-243.

Kulkarni, S., Bell, H., Hartman, J. L., \& Herman-Smith, R. L. (2013). Exploring individual and organizational factors contributing to compassion satisfaction, secondary traumatic stress, and burnout in domestic violence service providers. Journal of the Society for Social Work and Research, 4, 114-130.

Leiter, M. P., \& Maslach, C. (2006). The impact of interpersonal environment on burnout and organizational commitment. Journal of Organizational Behavior, 9, 297-308.

Lemieux-Cumberlege, A., \& Taylor, E. P. (2019). An exploratory study on the factors affecting the mental health and well-being of frontline workers in homeless services. Health and Social Care in the Community, 27, e367-e378.

Lewer, D., Aldridge, R. W., Menezes, D., Sawyer, C., Zaninotto, P., Dedicoat, M., ... \& Story, A. (2019). Health-related quality of life and prevalence of six chronic diseases in homeless and housed people: A cross-sectional study in London and Birmingham, England. British Medical Journal Open, 9, e025192.

Maas, C. J., \& Hox, J. J. (2005). Sufficient sample sizes for multilevel modeling. Methodology, 1, 86-92.

Manning, R. M., \& Greenwood, R. M. (2018). Microsystems of recovery in homeless services: The influence of service provider values on service users' recovery experiences. American Journal of Community Psychology, 61, 88-103.

Martins, D. C. (2008). experiences of homeless people in the health care delivery system: A descriptive phenomenological study. Public Health Nursing, 25, 420-430.

Maslach, C., \& Leiter, M. P. (2010). Burnout. In G. Fink (Ed.), Stress consequences: Mental, neuropsychological and socioeconomic (pp. 726-729). New York: Academic Press.

Maslach, C., Schaufeli, W. B., \& Leiter, M. P. (2001). Job burnout. Annual Review of Psychology, 52, 397-422.

Maton, K. I. (2008). Empowering community settings: Agents of individual development, community betterment, and positive social change. American Journal of Community Psychology, 41, 4-21.

McDonagh, T. (2011). Tackling homelessness and exclusion: Understanding complex lives. York, UK: Joseph Rowntree Foundation.

Neil, S. T., Nothard, S., Glentworth, D., \& Stewart, E. (2010). A study to evaluate the provision of psychosocial supervision within an Early Intervention team. The Cognitive Behaviour Therapist, 3, 58-70.

Nussbaum, M. C. (2001). Women and human development: The capabilities approach. Cambridge, UK: Cambridge University Press.

Nussbaum, M. C. (2011) . Creating capabilities: The human development approach. Cambridge, MA and London, England: Harvard University Press.

O'Shaughnessy, B. R., Manning, R. M., Greenwood, R. M., VargasMoniz, M. J., Loubière, S., Spinnewijn, F., ... \& The HOMEEU Consortium Study Group (2020). Home as a base for a well-lived life: Comparing the capabilities of homeless service users in housing first and the staircase of transition in Europe. 
Housing, Theory and Society. Advanced online publication. https://doi.org/10.1080/14036096.2020.1762725

Olivet, J., McGraw, S., Grandin, M., \& Bassuk, E. (2010). Staffing challenges and strategies for organizations serving individuals who have experienced chronic homelessness. The Journal of Behavioral Health Services and Research, 37, 226-238.

Osofsky, J. D., Putnam, F. W., \& Lederman, J. C. S. (2008). How to maintain emotional health when working with trauma. Juvenile and Family Court Journal, 59, 91-102.

Pines, A., \& Aronson, E. (1988). Career burnout: Causes and cures. New York: Free Press.

Purvanova, R. K., \& Muros, J. P. (2010). Gender differences in burnout: A meta-analysis. Journal of Vocational Behavior, 77, $168-185$.

Raudenbush, S. W., \& Bryk, A. A. S. (2002). Hierarchical linear models: Applications and data analysis methods. Thousand Oaks, CA: Sage.

Sacchetto, B., Ornelas, J., Calheiros, M. M., \& Shinn, M. (2018). Adaptation of Nussbaum's capabilities framework to community mental health: A consumer-based capabilities measure. American Journal of Community Psychology, 61, 32-46.

Salloum, A., Kondrat, D. C., Johnco, C., \& Olson, K. R. (2015). The role of self-care on compassion satisfaction, burnout and secondary trauma among child welfare workers. Children and Youth Services Review, 49, 54-61.

Santinello, M., Verzelletti, C., \& Altoè, G. (2006). Sviluppo e validazione del Link Burnout Questionnaire [Development and validation of Link Burnout Questionnaire]. Risorsa Uomo, 4, $1000-1012$.

Scanlon, C., \& Adlam, J. (2012). The (dis)stressing effects of working in (dis)stressed homelessness organisations. Housing, Care and Support, 15, 74-82.

Schaufeli, W. B., \& Bakker, A. B. (2003). UWES- Utrecht Work Engagement Scale: Test Manual. Departmemt of Psychology, Utrecht University.

Schaufeli, W. B., \& Bakker, A. B. (2004). Job demands, job resources and their relationship with burnout and engagement: A multi-sample study. Journal of Organizational Behavior, 25, 293-315.

Schaufeli, W. B., Bakker, A. B., \& Salanova, M. (2006). The measurement of work engagement with a short questionnaire: A cross-national study. Educational and Psychological Measurement, 66, 701-716.

Schaufeli, W. B., \& Taris, T. W. (2005). The conceptualization and measurement of burnout: Common ground and worlds apart. Work and Stress, 19, 256-262.

Sen, A. K. (1992). Inequality reexamined. Oxford: Clarendon Press.

Sen, A. (2004) Capabilities, lists, and public reason: Continuing the conversation. Feminist Economics, 10, 77-80. https://doi.org/ $10.1080 / 1354570042000315163$

Stanley, N., Manthorpe, J., \& White, M. (2007). Depression in the profession: Social workers' experiences and perceptions. British Journal of Social Work, 37, 281-298.

Stetler, C. B., Ritchie, J., Rycroft-Malone, J., Schultz, A., \& Charns, M. (2007). Improving quality of care through routine, successful implementation of evidence-based practice at the bedside: an organizational case study protocol using the Pettigrew and Whipp model of strategic change. Implementation Science, 2, $1-13$.

van Dongen, S. I., van Straaten, B., Wolf, J., Onwuteaka-Philipsen, B. D., van der Heide, A., Rietjens, J. A. C., \& van de Mheen, D. (2019). Self-reported health, healthcare service use and health-related needs: A comparison of older and younger homeless people. Health and Social Care in the Community, 27, 379-388.
VanDeusen, K. M., \& Way, I. (2006). Vicarious trauma: An exploratory study of the impact of providing sexual abuse treatment on clinicians' trust and intimacy. Journal of Child Sexual Abuse, 15, 69-85.

Wagaman, M. A., Geiger, J. M., Shockley, C., \& Segal, E. A. (2015). The role of empathy in burnout, compassion satisfaction, and secondary traumatic stress among social workers. Social Work, 60, 201-209.

Young, S. D. (2007). Psychotherapists working with homeless clients: The experience of stress, burnout symptoms, and coping (Doctoral dissertation, Antioch University).

\section{Appendix 1}

\section{HOME-EU (Horizon 2020 GA/726997) consortium study group}

José Ornelas (Principal Investigator), Maria J. VargasMoniz, Maria F Jorge-Monteiro (APPsyCI - Applied Psychology Research Center Capabilities and Inclusion, ISPA-Instituto Universitário, Rua Jardim do Tabaco, 34, 1149-041 Lisboa, Portugal); Ronni M. Greenwood, Rachel M. Manning, Branagh O'Shaughnessy (Department of Psychology, University of Limerick, Limerick, V94 T9PX, Ireland); Inês Almas, Teresa Duarte (AEIPS-The Association for Study and Psychosocial Integration; Housing First project: Casas Primeiro, Av. António José de Almeida, 26, 1000-043 Lisboa, Portugal); Francesca Disperati, Marta Gaboardi, Michela Lenzi, Massimo Santinello, Alessio Vieno (Department of Developmental and Social Psychology, University of Padova, Via Venezia, 8 -35131 Padova, Italy); Rita P. Marques, Maria Carmona, Américo Nave (Crescer-Community Intervention Association, Bairro Qta Cabrinha 3-E/F 1300-906 Lisboa, Portugal); Freek Spinnewijn (FEANTSA, European Federation of National Organisations Working with the Homeless, Chausse de Louvain 194 Bruxelles 1210, Belgique); Roberto Bernad, Borja Rivero, Martin Julián (Rais Fundación, C/ Ardemans 42, 28028 Madrid, Spain); Anna Bokszczanin, Barbara Zmaczynska-Witek, Skałacka Katarzyna, Aleksandra Rogowska (Institute of Psychology, Opole University, Pl. Staszica 1, 45-052 Opole, Poland); Sandra Schel, Yvonne Peters, Tessa van Loenen, Liselotte Raben, Judith R. Wolf (Radboud university medical center, Radboud Institute for Health Sciences, Impuls - Netherlands Center for Social Care Research, Nijmegen, The Netherlands); Ulla Beijer, Mats Blid, Hakan Kallmen (STAD, Stockholm Center for Psychiatry Research and Education, Karolinska Institutet, Norra Stationsgatan 69, 11364 Stockholm, Sweden); Teresa Bispo, Tiago Cruz, Carla Pereira (Câmara Municipal de Lisboa [The Lisboa City Council], Praça do Município 38, 1100-038 Lisboa, Portugal); Pascal Auquier, Junie M. Petit (Aix-Marseille Univ, School of medicine-La timone Medical Campus, 
EA3279 CEReSS-Health Service Research and Quality of Life Center, 27 Boulevard Jean Moulin, 13385 Marseille, France), Sandrine Loubière, Aurélie Tinland (Department of Research and Innovation, Support Unit for clinical research and economic evaluation, Assistance Publique-Hôpitaux de Marseille, 27 Boulevard Jean Moulin, 13385 Marseille, France). 